\title{
Residual recurrence risk of ischaemic cerebrovascular events: concept, classification and implications
}

Yongjun Wang ${ }^{1,2}$

To cite: Wang Y. Residual recurrence risk of ischaemic cerebrovascular events: concept, classification and implications. Stroke \& Vascular Neurology 2021;6: e000885. doi:10.1136/svn-2021-000885

Received 23 January 2021 Revised 2 March 2021 Accepted 3 March 2021 Published Online First 16 March 2021
Check for updates

(c) Author(s) (or their employer(s)) 2021. Re-use permitted under CC BY-NC. No commercial re-use. See rights and permissions. Published by BMJ.

${ }^{1}$ Department of Neurology, Beijing Tiantan Hospital, Capital Medical University, Beijing,

China

${ }^{2}$ China National Clinical

Research Center for

Neurological Diseases, Beijing, China

Correspondence to Professor Yongjun Wang; yongjunwang111@aliyun.com

\section{INTRODUCTION}

Patients with stroke still have substantial residual risk of stroke recurrence in spite of therapies following the guidelines. ${ }^{1}$ In addition to traditional vascular risk factors, conditions such as chronic inflammation, poor quality of care and variable response to standard therapy may contribute to the residual risk of stroke recurrence. ${ }^{2-4}$ Therefore, it is important to understand and classify the sources of residual risk to improve the prevention of stroke recurrence in patients already have a stroke.

\section{Conceptualisation and classification of the residual risk}

Residual risk is the amount of risk that remains after management or elimination of the known risk factors. Globally, the residual recurrence risk in patients who has a stroke has not been well estimated and varies between $3 \%$ and $6 \% .{ }^{156}$ From the perspective of clinical practice, residual risk could be classified into three types:

\section{Care-quality-based residual risk}

Such type of residual risk developed mainly because of poor individual adherence to treatment. Though secondary prevention measures such as the use of antithrombotic, antihypertensive, anti diabetic and lipid-lowering agents plus lifestyle modification have been recommended, adherence to these evidencebased therapies may be suboptimal in the real world, ${ }^{7}$ A multifaceted care quality intervention to improve adherence to guideline-based performance measures and secondary prevention measures among hospitalised patients can significantly reduce this type of residual risk. ${ }^{7}$ Another residual risk might be about achieving the target level of conditions such as in patients with hypercholesterolaemia. For example, low-density lipoprotein (LDL) cholesterol level was a common marker used to measure the effectiveness of cholesterollowering therapies. However, additional benefit from lipid-lowering agents beyond the recommended goals, such as an LDL level of $1.4 \mathrm{mmol} / \mathrm{L}$ or $0.78 \mathrm{mmol} / \mathrm{L}$ is not as clear, suggesting its role for residual risk. ${ }^{89}$

\section{Research-evidence-based residual risk}

This type of residual risk refers to the conditions raised from bench research or only with limited evidenced from clinical research. For example, inflammatory conditions are known to be associated with stroke recurrence. The Canakinumab Anti-Inflammatory Thrombosis Outcome Study (CANTOS) and Low Dose Colchicine (LoDoCo) 2 studies demonstrated a protective effect of antiinflammatory treatment in patients with coronary heart diseases. ${ }^{10} 11$ The ongoing CONVINCE (Colchicine for Prevention of Vascular Inflammation in Non-cardio Embolic Stroke) study evaluates the effect of low-dose colchicine in reducing the rate of recurrent stroke in patients who had a stroke (URL: http:/ /www.clinicaltrials.gov. NCT02898610). The result might shed some light. There are biological variations in the response to prevention therapies. For example, in those on clopidogrel, carriers of loss-of-function alleles of CYP2C19 1213 or protein biomarkers of glycated albumin, ${ }^{14}$ homocysteine ${ }^{15}$ and high-sensitivity $\mathrm{C}$ reactive protein ${ }^{16}$ may have a different response to clopidogrel. A recent study showed that residual risk was around $4.0 \%$ in a hypothetical scenario with further anti-inflammatory therapy and treatment for intracranial or extracranial arterial stenosis in patients who has a stroke under standard secondary prevention care (figure 1$).{ }^{17}$

Intracranial atherosclerotic arterial stenosis is an important cause of recurrence stroke. There is limited evidence either stenting or aggressive medical therapy may prevent recurrent stroke in these patients. ${ }^{6}$ The benefit of revascularisation of occluded carotid artery still needs further evidence. In addition, psychological factors may correlate with recurrent stroke. 


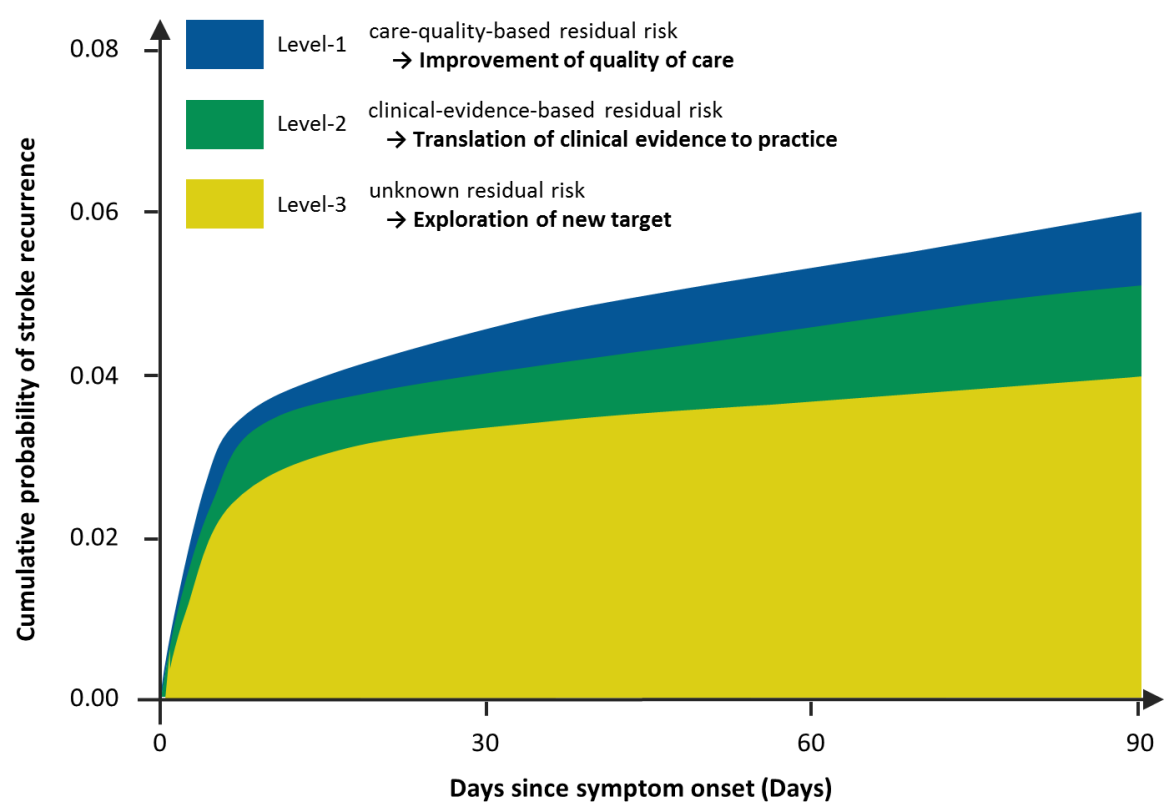

Figure 1 Classifications of stroke residual risk.

\section{Unknown residual risk}

Further research is needed to understand the unknown mechanism of recurrence and determine potential targets of intervention. Multiomics approaches may help with this effort by integrating data to better understand the relationship between different omics levels and their combined influence on underlying pathophysiology. ${ }^{18}$

\section{Implication and perspectives}

Lowering the residual risk of stroke recurrence calls for comprehensive measures including improving the quality of care, facilitating the translation of research to clinical evidence and practice, and exploring new targets for prevention. First, a multifaceted intervention to facilitate care quality is needed to improve individual adherence

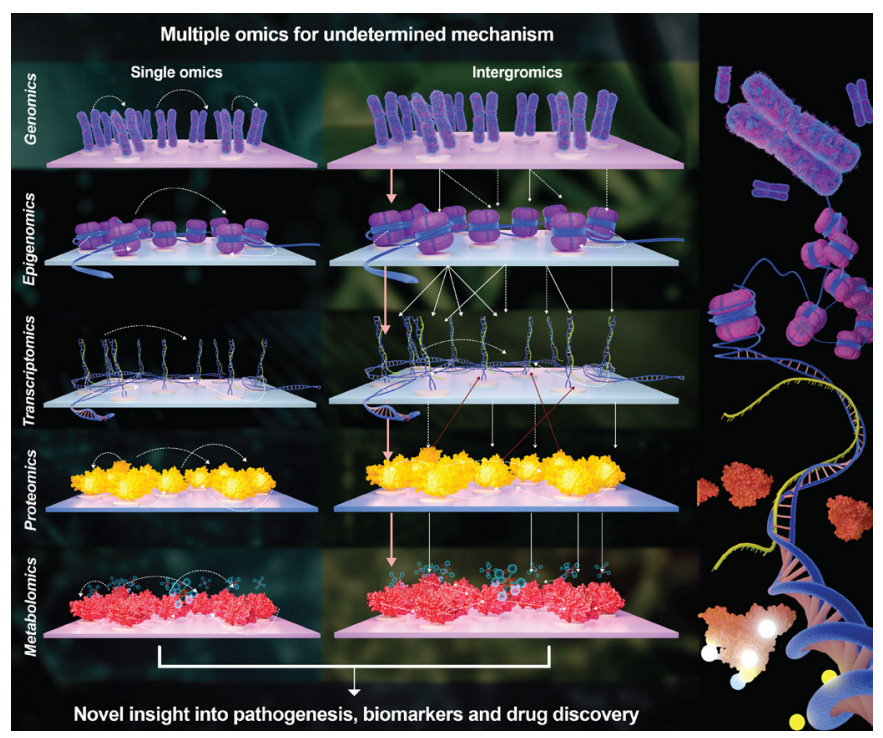

Figure 2 Multiple omics for undetermined mechanism of stroke residual risk. to guideline recommended therapies. Second, facilitating the translation of evidence of research into clinical practice will help reducing the residual risk. Given the progressive decline in the rate of recurrence, it is likely that the large sample size is required. ${ }^{19}$ Appropriate design of the clinical trial and strong international collaborations would be required. Lastly, we must continue to explore new targets to manage the residual risks, which may be done through multiomics approaches (figure 2). Advances in technology have enabled the use of high-throughput techniques based on large screening processes that can minimise selection bias and generate extensive lists of molecules for targets of novel drugs. ${ }^{20}$ These high-throughput technologies, including genomics, transcriptomics, epigenomics, proteomics and metabolomics, enable omics studies to integrate millions of markers concurrently. Compared with a single layer of 'omics' that only provides limited insight into the biological mechanisms of stroke, multiomics approaches integrate data to better understand the relationship between different omics levels as well as their combined influence on pathophysiological processes. ${ }^{18}$

Residual risk of stroke is a dynamic, evolving concept that may change around the recommendations of guidelines. However, standards of care are mediated through pathways not always directly addressed by our current management systems. Multiple new pharmacological agents targeting conceptually distinct pathophysiological targets have been explored to reduce residual risk. It is essential to continue this exploration of non-traditional risk factors through research, with a focus on multiomics approaches.

Contributors As a sole author, I formulated the research question and wrote draft of the manuscript. 
Funding This study was supported by grants from National Key R\&D Programme of China (2018YFC1312903), National Science and Technology Major Project (2017ZX09304018) and Beijing Municipal Science \& Technology Commission (D171100003017002).

Competing interests None declared.

Patient consent for publication Not required.

Provenance and peer review Not commissioned; externally peer reviewed.

Open access This is an open access article distributed in accordance with the Creative Commons Attribution Non Commercial (CC BY-NC 4.0) license, which permits others to distribute, remix, adapt, build upon this work non-commercially, and license their derivative works on different terms, provided the original work is properly cited, appropriate credit is given, any changes made indicated, and the use is non-commercial. See: http://creativecommons.org/licenses/by-nc/4.0/.

\section{REFERENCES}

1 Ji R, Liu G, Shen H, et al. Persistence of secondary prevention medications after acute ischemic stroke or transient ischemic attack in Chinese population: data from China national stroke Registry. Neurol Res 2013;35:29-36.

2 Patel KV, Pandey A, de Lemos JA. Conceptual framework for addressing residual atherosclerotic cardiovascular disease risk in the era of precision medicine. Circulation 2018;137:2551-3.

3 Ridker PM. Residual inflammatory risk: addressing the obverse side of the atherosclerosis prevention coin. Eur Heart J 2016;37:1720-2.

$4 \mathrm{Li} \mathrm{J}$, Zhao X, Meng X. High-Sensitive C-reactive protein predicts recurrent stroke and poor functional outcome: subanalysis of the clopidogrel in high-risk patients with acute Nondisabling cerebrovascular events trial. Stroke 2016;47:2025-30.

5 Bushnell CD, Olson DM, Zhao X, et al. Secondary preventive medication persistence and adherence 1 year after stroke. Neurology 2011;77:1182-90.

6 Chimowitz MI, Lynn MJ, Derdeyn CP, et al. Stenting versus aggressive medical therapy for intracranial arterial stenosis. $N$ Engl J Med 2011;365): :993-1003.

7 Wang Y, Li Z, Zhao X, et al. Effect of a multifaceted quality improvement intervention on hospital personnel adherence to performance measures in patients with acute ischemic stroke in China: a randomized clinical trial. JAMA 2018;320:245-54.

8 Cannon CP, Blazing MA, Giugliano RP, et al. Ezetimibe added to statin therapy after acute coronary syndromes. $N$ Engl J Med 2015;372:2387-97

9 Sabatine MS, Giugliano RP, Keech AC, et al. Evolocumab and clinical outcomes in patients with cardiovascular disease. N Engl J Med 2017;376:1713-22

10 Ridker PM, Everett BM, Thuren T, et al. Antiinflammatory therapy with canakinumab for atherosclerotic disease. N Engl J Med Overseas Ed 2017;377:1119-31.

11 Nidorf SM, Fiolet ATL, Mosterd A, et al. Colchicine in patients with chronic coronary disease. N Engl J Med 2020;383:1838-47.

12 Wang Y, Zhao X, Lin J, et al. Association between CYP2C19 lossof-function allele status and efficacy of clopidogrel for risk reduction among patients with minor stroke or transient ischemic attack. JAMA 2016;316:70-8.

13 Sun W, Li Y, Li J, et al. Variant recurrent risk among stroke patients with different CYP2C19 phenotypes and treated with clopidogrel. Platelets 2015;26:558-62.

14 Li J, Wang Y, Wang D, et al. Glycated albumin predicts the effect of dual and single antiplatelet therapy on recurrent stroke. Neurology 2015;84:1330-6.

$15 \mathrm{Li} \mathrm{J}$, Wang Y, Li H, et al. Homocysteine level predicts response to dual antiplatelet in women with minor stroke or transient ischemic attack: subanalysis of the chance trial. Arterioscler Thromb Vasc Biol 2020;40:839-46.

16 Li J, Wang A, Zhao X, et al. High-Sensitive C-reactive protein and dual antiplatelet in intracranial arterial stenosis. Neurology 2018;90:e447-54.

17 Yuesong Pan ZL, Li J. Residual risk and its risk factors for ischemic stroke and transient ischemic attack under standard secondary prevention care. journal of stroke. In Press 2020.

18 Sun YV, Hu Y-J. Integrative analysis of multi-omics data for discovery and functional studies of complex human diseases. Adv Genet 2016;93:147-90.

19 Amarenco P, Lavallée PC, Labreuche J, et al. One-Year risk of stroke after transient ischemic attack or minor stroke. N Engl J Med 2016;374:1533-42

20 Montaner J, Ramiro L, Simats A, et al. Multilevel omics for the discovery of biomarkers and therapeutic targets for stroke. Nat Rev Neurol 2020;16:247-64. 